\title{
ARTICLE OPEN \\ Unlocking the potential of weberite-type metal fluorides in electrochemical energy storage
}

\author{
Holger Euchner ${ }^{1}$, Oliver Clemens $\mathbb{1 D}^{2,3}$ and M. Anji Reddy ${ }^{1}$
}

Sodium-ion batteries (NIBs) are a front-runner among the alternative battery technologies suggested for substituting the state-ofthe-art lithium-ion batteries (LIBs). The specific energy of Na-ion batteries is significantly lower than that of LIBs, which is mainly due to the lower operating potentials and higher molecular weight of sodium insertion cathode materials. To compete with the high energy density of LIBs, high voltage cathode materials are required for NIBs. Here we report a theoretical investigation on weberitetype sodium metal fluorides (SMFs), a new class of high voltage and high energy density materials which are so far unexplored as cathode materials for NIBs. The weberite structure type is highly favorable for sodium-containing transition metal fluorides, with a large variety of transition metal combinations $\left(\mathrm{M}, \mathrm{M}^{\prime}\right)$ adopting the corresponding $\mathrm{Na}_{2} \mathrm{MM}^{\prime} \mathrm{F}_{7}$ structure. A series of known and hypothetical compounds with weberite-type structure were computationally investigated to evaluate their potential as cathode materials for NIBs. Weberite-type SMFs show two-dimensional pathways for $\mathrm{Na}^{+}$diffusion with surprisingly low activation barriers. The high energy density combined with low diffusion barriers for $\mathrm{Na}^{+}$makes this type of compounds promising candidates for cathode materials in NIBs.

npj Computational Materials (2019)5:31; https://doi.org/10.1038/s41524-019-0166-3

\section{INTRODUCTION}

Post lithium-ion batteries (LIBs) are becoming highly relevant for future energy storage. Among the post LIB technologies, sodiumion batteries (NIBs) are of immediate interest due to the conceptual similarities between LIBs and NIBs, which may enable the transformation of knowledge and experience from LIBs to NIBs. ${ }^{1,2}$ Sodium sources are abundant and widespread. Consequently, sodium precursors are low cost and attractive for commercial use. Moreover, Na does not form alloys with $\mathrm{Al}$, which enables the use of low-cost Al as anode current collector instead of more expensive $\mathrm{Cu}^{3}$ These factors significantly contribute to lowering the cost of NIBs. Besides economic advantages, the desolvation energies of $\mathrm{Na}^{+}$are significantly lower as compared to $\mathrm{Li}^{+}$and $\mathrm{Mg}^{2+}$ (in a given solvent), which may enable the design of high-power density battery systems based on fast $\mathrm{Na}^{+}$transport. ${ }^{4}$ However, on the downside, the standard reduction potential of $\mathrm{Na}$ is $-2.73 \mathrm{~V}$ (vs. standard hydrogen electrode), i.e., $0.3 \mathrm{~V}$ lower than that of $\mathrm{Li}$, which is reflected in lower operating potentials of the current $\mathrm{Na}$-ion systems. Also, the higher molecular weight of sodium cathode materials results in lower theoretical capacity. Hence, the state-ofthe-art NIBs exhibit lower specific energy in comparison to the corresponding LIBs. Consequently, to compete with the high energy density of LIBs, high-voltage cathode materials are required for NIBs.

Two major classes of compounds have been investigated as cathode materials for NIBs: layered metal oxides and polyanionbased compounds. In comparison, both material types show some benefits as well as disadvantages with respect to each other. Layered sodium metal oxides $\left(\mathrm{Na}_{x} \mathrm{MO}_{2}\right)$ crystallize in several polytypes, which are categorized as $\mathrm{O} 3 / \mathrm{O}^{\prime} 3$ and $\mathrm{P} 2$ types. ${ }^{5}$ Sodium can be reversibly extracted and inserted from $\mathrm{Na}_{x} \mathrm{MO}_{2}(\mathrm{M}=\mathrm{V}, \mathrm{Cr}$, $\mathrm{Mn}, \mathrm{Fe}, \mathrm{Co}, \mathrm{Ni}$ ) type compounds within certain capacity limits. ${ }^{6-11}$ In the case of the O3-type compounds, extraction of Na beyond $x$ $<0.5$ leads to irreversible structural changes (layered to rock salt transition), imposing large irreversible capacity losses and capacity fading. ${ }^{12,13}$ In the case of P2-type compounds, the depletion of $\mathrm{Na}^{+}$between the layers triggers the repulsive interaction between $\left(\mathrm{MO}_{2}\right)_{n}$ layers, leading to the gliding of $\mathrm{MO}_{2}$ sheets in the $a-b$ plane to avoid close oxygen-oxygen contacts, which is associated with huge volume changes (up to $20 \%$ ). ${ }^{10}$ In both cases, cation codoping in the transition metal (TM) layer was shown to be effective and high reversible capacities were observed for cation co-doped O3-type $\mathrm{NaFe}_{1 / 2} \mathrm{Co}_{1 / 2} \mathrm{O}_{2}, \mathrm{NaNi}_{1 / 3} \mathrm{Fe}_{1 / 3} \mathrm{Co}_{1 / 3} \mathrm{O}_{2}, \mathrm{NaNi}_{1 / 3}$ $\mathrm{Fe}_{1 / 3} \mathrm{Mn}_{1 / 3} \mathrm{O}_{2}, \mathrm{NaNi}_{1 / 4} \mathrm{Fe}_{1 / 4} \mathrm{Co}_{1 / 4} \mathrm{Mn}_{1 / 4} \mathrm{O}_{2}$, P2-type $\mathrm{Na}_{x}\left[\mathrm{Fe}_{1 / 2} \mathrm{Mn}_{1 / 2}\right]$ $\mathrm{O}_{2}$, and $\mathrm{Na}_{0.67} \mathrm{Mn}_{1-\mathrm{x}} \mathrm{Mg}_{\mathrm{x}} \mathrm{O}_{2}(0 \leq x \leq 0.2)$ and intergrowths of $\mathrm{P} 2$ and O3-type $\mathrm{Na}_{0.76} \mathrm{Mn}_{0.5} \mathrm{Ni}_{0.3} \mathrm{Fe}_{0.1} \mathrm{Mg}_{0.1} \mathrm{O}_{2} \cdot{ }^{11,14-19}$ Besides $\mathrm{P} 2$ and O3-type compounds, P3-type layered compounds were actively investigated as cathode materials for NIBs. ${ }^{2,21}$

In the second class, the polyanion-based compounds, layered $\mathrm{Na}_{2} \mathrm{FePO}_{4} \mathrm{~F}, \mathrm{Na}_{3} \mathrm{~V}_{2}\left(\mathrm{PO}_{4}\right)_{2}(\mathrm{~F}, \mathrm{O})_{3}$, NASICON-type $\mathrm{Na}_{3} \mathrm{~V}_{2}\left(\mathrm{PO}_{4}\right)_{3}$, sidorenkite $\mathrm{Na}_{3} \mathrm{MnPO}_{4} \mathrm{CO}_{3}$, and alluaudite-type $\mathrm{Na}_{2} \mathrm{Fe}_{2}\left(\mathrm{SO}_{4}\right)_{3}$ are most promising candidates. ${ }^{22-27}$ Here carbon-coated compounds deliver in most cases capacities close to the theoretical specific capacity. ${ }^{23-25}$ However, their specific energies are still low. Among these polyanionic compounds, $\mathrm{Na}_{3} \mathrm{~V}_{2}\left(\mathrm{PO}_{4}\right)_{2}(\mathrm{~F}, \mathrm{O})_{3}$ is of particular interest due to its high specific energy of $500 \mathrm{Wh} \mathrm{kg}^{-1}$, which can be increased up to $600 \mathrm{Wh} \mathrm{kg}^{-1}$ by the insertion of an additional sodium. ${ }^{28}$ Iron-based $\mathrm{Na}_{2} \mathrm{Fe}_{2}\left(\mathrm{SO}_{4}\right)_{3}$ also shows high specific energy $\left(450 \mathrm{Wh} \mathrm{kg}^{-1}\right)$, yet the stability of this compound is a

\footnotetext{
${ }^{1}$ Helmholtz Institute Ulm (HIU) Electrochemical Energy Storage, Helmholtz str.11, 89081 Ulm, Germany; ${ }^{2}$ Materials Design by Synthesis, Technical University Darmstadt, Alarich-

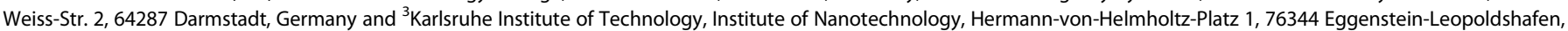
Germany

Correspondence: M. Anji Reddy (munnangi.reddy@kit.edu)
}

Received: 9 October 2018 Accepted: 11 February 2019

Published online: 06 March 2019 
concern. Apart from these two classes of materials, recently we reported a new sodium vanadium oxy-phosphate, $\mathrm{Na}_{2} \mathrm{~V}_{3} \mathrm{P}_{2} \mathrm{O}_{13}$ with a specific energy of $356 \mathrm{Wh} \mathrm{kg}^{-1}$ as sustainable cathode material for NIBs. ${ }^{29} \mathrm{~A}$ comparison of the specific energies of cathode materials for state-of-the-art LIBs and NIBs are listed in the Table S1. Conclusively, layered $\mathrm{Na}_{x} \mathrm{MO}_{2}$-type compounds possess higher theoretical capacities, but the theoretical specific energies are not achieved. Carbon-coated polyanion-based compounds essentially deliver their theoretical specific capacities, yet their specific energy is significantly lower. Apart from layered metal oxides and polyanion-based compounds, metal fluorides have been found to exhibit great potential as cathode materials for NIBs. They combine the advantages of metal oxides and polyanionic compounds.

In comparison to metal oxides, for which oxygen release is often problematic, metal fluorides offer higher oxidative stability and, moreover, generate high electrode potentials similar to those of polyanionic compounds. The molar weight of fluorides is significantly lower in comparison to a polyanionic moiety (e.g., $3 \mathrm{~F}^{-}: 56.99 \mathrm{~g} \mathrm{~mol}^{-1}, \mathrm{PO}_{4}{ }^{3-}: 94.97 \mathrm{~g} \mathrm{~mol}^{-1}$ ) which results in an increased specific capacity as well as higher specific energy. Metal fluorides are electrical insulators, which could, however, be alleviated by suitable conductive coatings or additives similar to the case of polyanion-based compounds. ${ }^{23,24}$ Furthermore, owing to the monovalent nature of fluoride, metal fluorides offer high anion-to-cation ratios (F/M). Consequently, various transition metal fluorides exhibit open structures with high coordination of the interstitial sites, which makes them suitable for accommodating $\mathrm{Na}^{+}$(but often not $\mathrm{Li}^{+}$ions). There are several families of sodium-containing metal fluorides, which are interesting for sodium insertion/deinsertion chemistry. One such family are perovskite-type $\mathrm{NaMF}_{3}(\mathrm{M}=\mathrm{Fe}, \mathrm{Mn}, \mathrm{Ni}$, and $\mathrm{Co})$ compounds. Gocheva et al. synthesized $\mathrm{NaMF}_{3}(\mathrm{M}=\mathrm{Fe}, \mathrm{Mn}$, and $\mathrm{Ni})$ by mechanochemical milling and studied them as cathode materials for $\mathrm{NIBs}^{30} \mathrm{NaFeF}_{3}$ delivered an initial charge capacity of $128 \mathrm{mAh}$ $\mathrm{g}^{-1}$ at an average voltage of $2.7 \mathrm{~V}$, with large polarization between charge and discharge, and rapid capacity fading. In the case of $\mathrm{NaMnF}_{3}$ and $\mathrm{NaNiF}_{3}$, the initial charge capacity was limited to only $40 \mathrm{mAh} \mathrm{g}^{-1}$. Later it turned out that the charge capacity observed in these compounds was mainly due to side reactions. ${ }^{31}$ Subsequently, few authors investigated the sodium insertion properties of the $\mathrm{NaMF}_{3}$ system with a focus on $\mathrm{NaFeF}_{3} .{ }^{32}$ Kitajou et al. synthesized $\mathrm{NaFeF}_{3}$ by the roll-quench method and showed that by slow charging to $4.5 \mathrm{~V}$ the theoretical capacity of $197 \mathrm{mAh}$ $\mathrm{g}^{-1}$ could be achieved. ${ }^{33}$ Unfortunately, the electrochemical results from all these studies indicate a slow diffusion of $\mathrm{Na}^{+}$in these structures. Sluggish $\mathrm{Na}^{+}$diffusion in combination with poor electronic conductivity would result in significant overvoltage and poor electrochemical performance. Another large family of sodium metal fluorides (SMFs) is based on the weberite-type structure, which was not explored earlier for NIBs. Here we investigate a series of known and hypothetical (i.e., so far not prepared) compounds with the weberite-type structure as cathode materials for NIBs.

The structure type of the weberite family is named after the parent compound, the mineral $\mathrm{Na}_{2} \mathrm{MgAlF}_{7}$. The structure can be
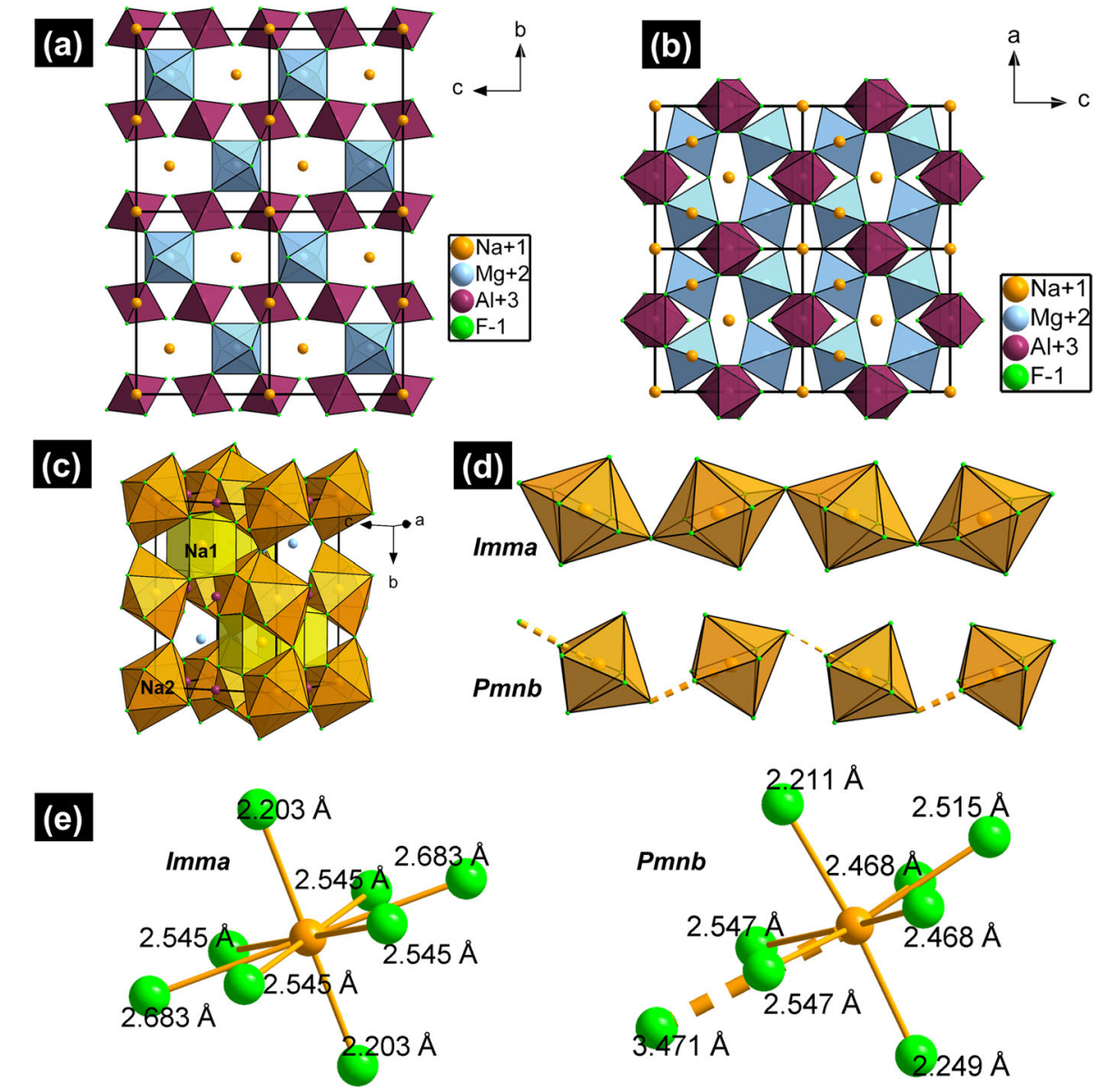

Fig. 1 Crystal structure of the orthorhombic $(I m m a)$ modification of $\mathrm{Na}_{2} \mathrm{MgAlF}_{7}$ along different viewing directions highlighting the different interconnectivity of $\mathrm{M} / \mathrm{M}^{\prime}$ and $\mathrm{Na1} / 2$ polyhedra: $\mathrm{M} / \mathrm{M}^{\prime}$ networks along [100] $\mathbf{a}$, along [010] b, and Na1/2 subnetwork tilted along [100] c. Changes of bond distances for the $\mathrm{Na} 2$ octahedron within the lower symmetry (Pmnb) as compared to the high-symmetry modification $(\mathrm{Imma}) \mathbf{d}$; $\mathrm{Na}-\mathrm{O}$ bond lengths of Na polyhedra e 
viewed as a four-fold superstructure of the cubic fluorite structure $\left(\mathrm{CaF}_{2}\right)$. The ordering of cations and anion vacancies, as well as a shift of some of the anions, can be described by a generalized formula $A^{(4 a)} A^{\prime(4 d)} M^{(4 b)} M^{\prime(4 c)} F_{7}^{(4 e, 8 h, 16 j)} \square$ (with $\mathrm{Na}_{2} \mathrm{MgAlF}_{7}$ crystallizing in the most prominent structure variant, a $\sqrt{2} \times 2 \times \sqrt{2}$ fluorite superstructure of space group $/ m m a) .{ }^{34-36}$ For $\mathrm{Na}_{2} \mathrm{MgAlF}_{7}$, the sodium ions occupy the $4 a$ and $4 d$ sites, whereas $\mathrm{Mg}$ and $\mathrm{Al}$ are located on the $4 b$ and $4 c$ sites. The vacancy ordering and the shift of the fluoride anions results in octahedral coordination for both $\mathrm{Mg}$ and $\mathrm{Al}$ cations, whereas the $\mathrm{Na}$ cations maintain the eight-fold coordination, typical for the fluorite structure. The Na1 coordination polyhedron is similar to a distorted cube. However, strong distortions of the coordination can be found for the $\mathrm{Na} 2$ cations, and the resulting coordination polyhedron is best described as a $6+2$ coordination of a slightly distorted bicapped hexagon. The cation ordering results in the formation of tilted chains of corner-sharing $\mathrm{MgF}_{6}$ octahedra running along the [100] direction of the unit cell (Fig. 1a). The AlF 6 octahedra interconnect two chains of $\mathrm{MgF}_{6}$ octahedra via four of their corners as shown in Fig. $1 \mathrm{a}$, whereas there is no connectivity among AlF $_{6}$ octahedra. The sodium ions are located within the resulting cavities, which form channels running along the [010] and [100] directions (Fig. $1 \mathrm{a}, \mathrm{b}$ ). Each type of sodium ion (cube coordinated and $6+2$ coordinated) forms a one-dimensional channel-like substructure of interconnected polyhedra. $\mathrm{Na} 1(4 d)$ is occupying the channels running along the $a$ axis, and $\mathrm{Na} 2(4 a)$ is occupying the channels along the $b$ axis (also see computational results presented later in this article). The interconnectivity of the polyhedra is different for the two sites: The $\mathrm{Na} 1$ (cube) coordination polyhedra are interconnected through edge-sharing fluoride ions (see Fig. S2), while those of the $\mathrm{Na} 2$ sites are interconnected through the corner-sharing fluoride ions of strongly tilted polyhedra (Fig. 1d). Furthermore, the $\mathrm{Na} 1$ and $\mathrm{Na} 2$ sites are connected through polyhedron edges and empty common space, resulting in a structure with two-dimensional (2D) $\mathrm{Na}^{+}$diffusion. The $\mathrm{Na}^{+}$ diffusion can be assumed to proceed along a curved trajectory in the respective channels through the faces of the polyhedra. Hence, these faces can be identified as the bottleneck for $\mathrm{Na}^{+}$diffusion, yet they could be altered by doping. Since the weberite structure is in principle derived from a cubic close packing of the cations, one can easily imagine that there are no further energetically favorable sites that might be filled by additional sodium ions. Consequently, only the removal of sodium under oxidation of the $M / M^{\prime}$ cations seems plausible. In this respect, the principal stability of a sodiumfree lattice is well indicated by the existence of some weberite fluoride hydrates $M^{\prime} M^{\prime} F_{5}\left(\mathrm{H}_{2} \mathrm{O}\right)_{2}$ which are-apart from the protons -isostructural to desodiated $\mathrm{MM}^{\prime} \mathrm{F}_{7}{ }^{37}$

Furthermore, three other variants of the weberite-type structure are known. ${ }^{36}$ A second orthorhombic modification of the weberite-type structure $(P m n b)$ exists, which can be derived from the modification with Imma symmetry by further tilting of the polyhedra (exemplified for the $\mathrm{Na} 1$ sublattice in Fig. 1d) under maintenance of the $\mathrm{Na}$ and $\mathrm{M} / \mathrm{M}^{\prime}$ orbits (also see symmetry tree shown in Fig. S3). Apart from these two orthorhombic weberite modifications (2O, Fig. S2), there are also trigonal (3T) and monoclinic (2M) weberite modifications. ${ }^{36}$ These also show structural similarity to the fluorite-type structure; however, they are no direct super-/subgroups of the orthorhombic structure, and their symmetries and splitting of the cation sites are clearly different (Fig. S3). The sublattices of sodium and $M / M^{\prime}$ cations of the two orthorhombic modifications are similar to the distribution of $A$ and $B$ ions in the pyrochlore-type structure with composition $\mathrm{A}_{2} \mathrm{~B}_{2} \mathrm{O}_{7}$. Although the trigonal modification can as well be derived from the pyrochlore-type structure, its distribution of $\mathrm{Na}$ and $\mathrm{M} / \mathrm{M}^{\prime}$ atoms on the different orbits does not follow the $A / B$ scheme of the pyrochlore aristotype. Regardless of this, the threedimensional (3D) network of edge-sharing sodium coordination polyhedra is maintained for this modification (see Fig. S2). The monoclinic modification is even more complex. Here the $\mathrm{Na}$ and $\mathrm{M} / \mathrm{M}^{\prime}$ ions cannot be grouped in such a way that the $A / B$ splitting scheme of the pyrochlore aristotype is maintained. However, the structural distortions are in principle similar to the orthorhombic and trigonal modifications, again with the existence of a 3D network of sodium coordination polyhedra (Fig. S2).

For both, the trigonal and the monoclinic modification, sodium can be found in $6+2$ and cube-type coordination. Interestingly, the same building blocks of interconnected sodium polyhedra as for the orthorhombic modifications can be found (see Fig. S2, exemplified for the monoclinic in comparison to the orthorhombic modification).

The formation of $2 \mathrm{O}$ and $2 \mathrm{M}$ modifications is observed for an increased size of the divalent cations (Fig. 2). Since the principle subnetwork of the A cations is maintained, they can still be regarded to be suitable for NIBs: Nevertheless, it would be of great interest in this respect to understand the structure chemical

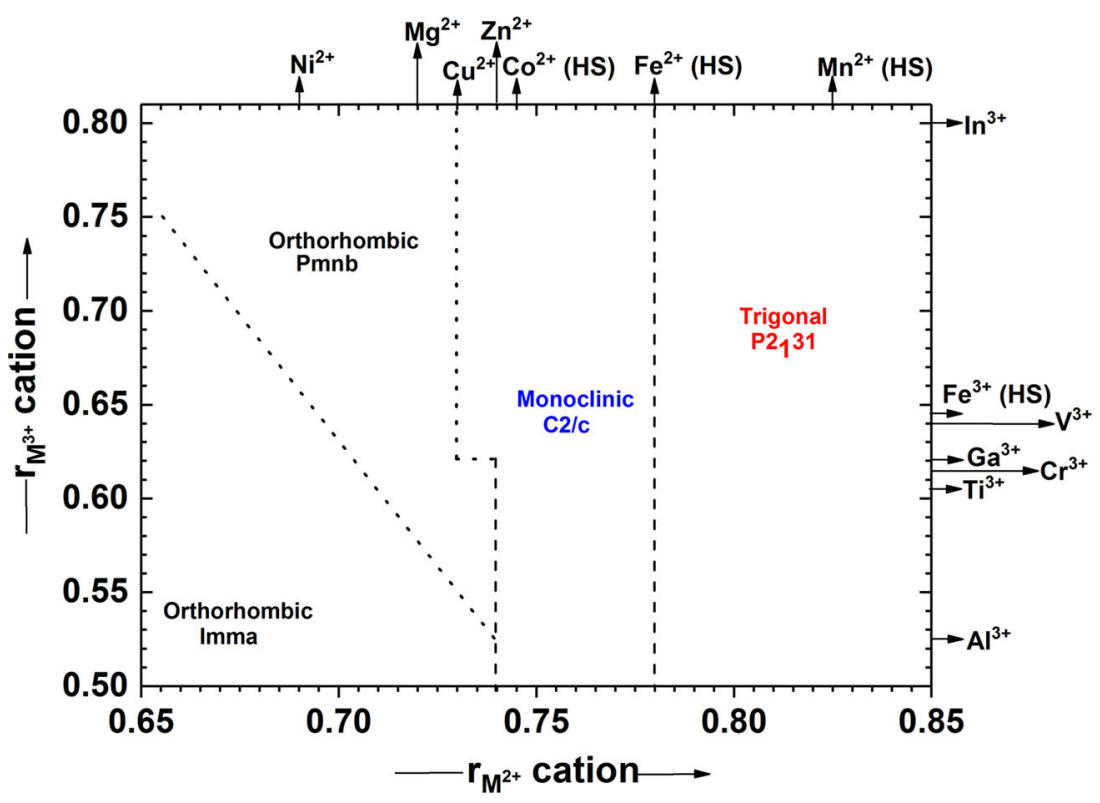

Fig. 2 Classification of weberite-type sodium metal fluorides based on the space group and metal ion radii 
implications for potential differences of the distinct weberite modifications. The structural distortions can also be expected to show some implications for the ion conduction pathways, which are available for sodium extraction. Crystallographically different sites always imply energetic inequivalency, and this may result in an alteration of the energy profiles and activation barriers for the different modifications. Further, this could also imply differences in the voltage profile, since one could imagine the deinsertion of certain sodium ions to be favorable over others.

The weberite-type structure seems to be highly favorable for sodium-containing transition metal fluorides, with many compounds of composition $\mathrm{Na}_{2} \mathrm{MM}^{\prime} \mathrm{F}_{7}$ adopting this structure. By replacing $\mathrm{Mg}^{2+}$ with other divalent cations and $\mathrm{Al}^{3+}$ with other trivalent cations of comparable sizes, various SMFs can be formulated, and many of them are already known. ${ }^{36}$ By choosing compounds with active redox metals in place of $\mathrm{Mg}$ and $\mathrm{Al}$, high theoretical capacities and high voltages may be realized. For example, $\mathrm{Na}_{2} \mathrm{FeVF}_{7}$ can deliver a theoretical capacity of $187 \mathrm{mAh}$ $\mathrm{g}^{-1}$ by oxidizing $\mathrm{Fe}^{2+}$ to $\mathrm{Fe}^{3+}$ and $\mathrm{V}^{3+}$ to $\mathrm{V}^{4+}$ and simultaneously extracting two sodium ions. If the extraction of two sodium ions was found to destabilize the structure, this could be compensated by controlling the amount of extracted sodium ions by partly substituting with redox-inactive metals like $\mathrm{Mg}$ or $\mathrm{Al}$ (as also done for layered compounds in the field of $\mathrm{LIBs}^{18}$ ) or by limiting the voltage window.

We have selected several weberite-type SMFs for a theoretical investigation of their suitability as cathode materials for NIBs. As discussed previously, there exist several variants of the weberite structure, which differ with respect to symmetry and arrangement of the common structural building blocks. For our computational investigation, we have limited the structural complexity to investigating the simplest weberite variant that contains 44 atoms per unit cell and crystallizes in space group Imma. We have investigated a large number of compounds with different compositions that were reported to crystallize in one of the weberite-type structure types. However, regardless of the experimentally observed symmetry, all compounds have been described in the Imma symmetry for computational reasons. Therefore, the reader should keep in mind that some of the investigated structures possibly do not represent the ground state structure, and consequently, deviations between experiment and calculations may be expected for these compounds. It however has to be pointed out that in the case of the parent compound $\mathrm{Na}_{2} \mathrm{MgAlF}_{7}$ all structural modifications are energetically almost identical (they differ $<1.0 \mathrm{meV}^{-1}{ }^{-1}$ ). This together with the fact that all structural modifications consist of the same building blocks makes it reasonable to conclude that the different space groups will also be energetically very close for the other investigated compounds.

Moreover, since the same building blocks of interconnected sodium polyhedra can be found for the different weberite modifications (see Fig. S2, exemplified for the monoclinic in comparison to the orthorhombic modification), we assume that the diffusion processes occurring in the different weberite modifications can be approximated by the inter-diffusion of $\mathrm{Na} 1-\mathrm{Na} 1, \mathrm{Na} 2-\mathrm{Na} 2$, and $\mathrm{Na} 1-\mathrm{Na} 2$ occurring in the orthorhombic modification. Especially the Na1-Na1 diffusion path is essentially equivalent in the different modifications, validating the choice of the orthorhombic high symmetry modification (Imma) as representative to approximate diffusion barriers within the compounds.

Here we intended to investigate the impact of certain elements on the performance of the material. Therefore, we consider it a reasonable assumption that the reported results can give a good estimate for the potential use of a given compound as cathode material in NIBs.

Moreover, substitution of small amounts of a given element in a compound that crystallizes in space group Imma may improve the performance of the latter while still maintaining the high symmetry structure type. For such an approach, the knowledge about the impact of a certain element will be crucial and can be provided by our model calculations. Therefore, we have extended our investigations to combinations that are so far unknown (highlighted with bold in Table S2) but are, due to the ionic sizes (Fig. 2), likely to exist in space group Imma. For example, $\mathrm{Ti}^{3}$ ${ }^{+}$-based weberite fluorides are unknown. Based on the ionic size consideration, $\mathrm{Ti}^{3+}$ compounds are, however, likely to adopt the Imma-type weberite variant.

To shed light on the synthesis of weberite-type metal fluorides, we briefly reviewed the synthesis methods of metal fluorides. Mechanical milling becomes an important tool for the synthesis of carbon metal fluoride nanocomposites. ${ }^{38-40}$ Several ternary fluoride ion transporting solid electrolytes and carbon-metal fluoride nanocomposites were synthesized by high-energy mechanical milling. ${ }^{41-43}$ Few chemical methods were reported for the synthesis of metal fluorides, but these methods are mainly applied for the synthesis of binary metal fluorides. ${ }^{44-47}$ A common chemical method used for the synthesis of ternary metal fluorides is based on the metal-trifluoroacetate complex, where $\mathrm{CF}_{3} \mathrm{COO}^{-}$ acts as a fluoride source during the heating process. This method was used for the synthesis of LIB cathode materials, $\mathrm{LiNiFeF}_{6}$ and $\mathrm{LiMgFeF}_{6}{ }^{48,49}$ The weberite-type metal fluorides are possible to synthesize by mechanical milling followed by sintering at appropriate temperatures if required or by a metaltrifluoroacetate complex method. Traditionally, weberite-type metal fluorides were synthesized by solid-state reaction of the respective metal fluorides at high temperatures. ${ }^{34,35}$

\section{RESULTS}

Screening real and virtual compounds reveals the potential of weberite-type metal fluorides as cathode materials for NIBs. The full list of computationally investigated compounds and corresponding physical properties are given in Table S2. The theoretical specific capacity of the investigated compounds spans $95-210 \mathrm{mAh} \mathrm{g}^{-1}$. Here the determining factor is the number of redox-active TMs and the molecular mass per formula unit. The following TM redox couples were considered for calculating the theoretical specific capacity of the proposed compounds: $\mathrm{Ti}\left(\mathrm{Ti}^{3+} / \mathrm{Ti}^{4+}\right), \mathrm{V}\left(\mathrm{V}^{3+} \mathrm{N}^{4+}\right.$ and $\left.\mathrm{V}^{4+} \mathrm{N}^{5+}\right), \mathrm{Cr}\left(\mathrm{Cr}^{3+} / \mathrm{Cr}^{4+}\right), \mathrm{Mn}$ $\left(\mathrm{Mn}^{2+} / \mathrm{Mn}^{3+}\right)$, Fe $\left(\mathrm{Fe}^{2+} / \mathrm{Fe}^{3+}\right.$ and $\left.\mathrm{Fe}^{3+} / \mathrm{Fe}^{4+}\right), \mathrm{Co}\left(\mathrm{Co}^{2+} / \mathrm{Co}^{3+}\right), \mathrm{Ni}$ $\left(\mathrm{Ni}^{2+} / \mathrm{Ni}^{3+}\right)$, and $\mathrm{Cu}\left(\mathrm{Cu}^{2+} / \mathrm{Cu}^{3+}\right) . \mathrm{Mg}, \mathrm{Al}, \mathrm{Sc}$, and $\mathrm{Zn}$ were assumed as inactive redox elements $\left(\mathrm{Mg}^{2+}, \mathrm{Zn}^{2+}, \mathrm{Al}^{3+}, \mathrm{Sc}^{3+}\right)$. We have also investigated compounds composed only of inactive redox elements to gain an understanding of the sodium diffusion behavior. The open circuit voltage (OCV) of the different compounds is calculated via Eq. (1) (see methods). Depending on the possible oxidation states of the involved TMs, either one or two Na per f.u. were extracted for determining the OCV. This results in a wide range of OCV values, spanning from about $\sim 1.7$ (for Ti-containing compounds) to $\sim 5.1 \mathrm{~V}$ vs. $\mathrm{Na} / \mathrm{Na}^{+}$(for $\mathrm{Ni}-$ containing materials) as can be inferred from Fig. 3 and Table S2.

A plot relating gravimetric capacity, voltage (vs. $\mathrm{Na} / \mathrm{Na}^{+}$), and gravimetric energy density of different weberite-type phases is shown in Fig. 3. The calculated values refer to the pure cathode materials. Also, the calculated values are compared with the stateof-the-art cathode materials for LIBs and NIBs (experimentally determined). Corresponding values for the state-of-the-art electrode materials are given in Table S1. The redox potentials strongly depend on the redox-active TMs. While the $\mathrm{Ti}^{3+} / \mathrm{Ti}^{4+}$ redox couple in $\mathrm{Na}_{2} \mathrm{MgTiF}_{7}$ results in the lowest observed potential of $1.69 \mathrm{~V}, \mathrm{Ni}$-containing compounds show the highest potentials with voltages of up to $5 \mathrm{~V}$. Such high voltages for $\mathrm{Ni}^{2}$ ${ }^{+} / \mathrm{Ni}^{3+}$ redox couples are expected considering the sodium extraction potential of $4.8 \mathrm{~V}$ reported for $\mathrm{Na}_{4} \mathrm{Ni}_{3}\left(\mathrm{PO}_{4}\right)_{2}\left(\mathrm{P}_{2} \mathrm{O}_{7}\right)$, also based on $\mathrm{Ni}^{2+} / \mathrm{Ni}^{3+}$ and $\mathrm{Ni}^{3+} / \mathrm{Ni}^{4+}$ redox couples. ${ }^{50}$ Owing to the 


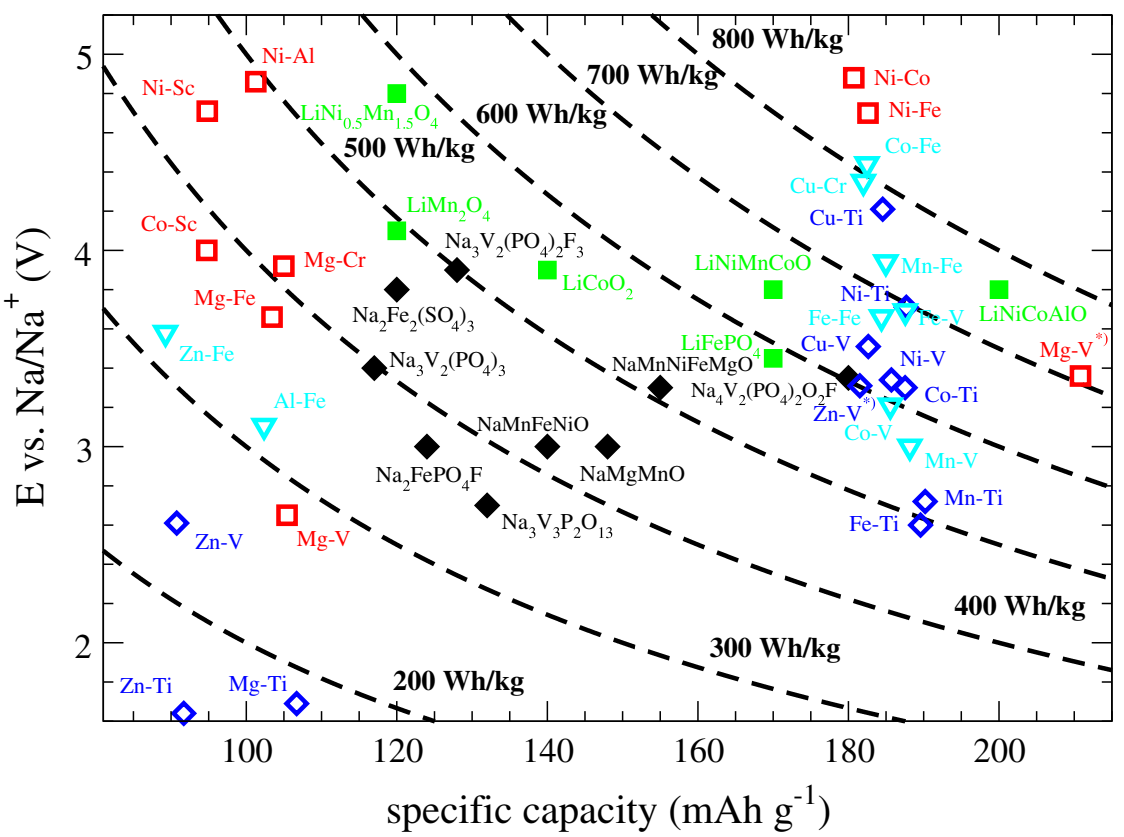

Fig. 3 Comparison of voltage, specific capacity, and specific energies of weberite-type metal fluorides in comparison with the experimentally achieved values of state-of-the-art cathode materials for sodium-ion batteries and lithium-ion batteries. ${ }^{15,18,19,23,25,27,28,52}$ The weberites are depicted in three different colors, which refer to known compounds that crystallize in space group Imma (red), unknown compounds that are likely to crystallize in Imma (blue), and compounds that so far have only been found in other space group but are calculated in Imma (cyan). $\left.\mathrm{Mg}-\mathrm{V}^{*}\right)$ and $\left.\mathrm{Zn}-\mathrm{V}^{*}\right)$ correspond to $\left(\mathrm{V}^{3+} \mathrm{N}^{5+}\right)$ redox couples while $\mathrm{Mg}-\mathrm{V}$ and $\mathrm{Zn}-\mathrm{V}$ stand for $\left(\mathrm{V}^{3+} / \mathrm{V}^{4+}\right)$ couples. Black symbols correspond to other NIB cathode materials, and green symbols depict state-of-the-art LIB cathode materials (for LIB cathode materials, the voltages are vs. Li/ $\mathrm{Li}^{+}$). In the figure, the following abbreviations are used: $\mathrm{NaMnFeMgO}$ (for $\mathrm{Na}_{0.76} \mathrm{Mn}_{0.5} \mathrm{Ni}_{0.3} \mathrm{Fe}_{0.1} \mathrm{Mg}_{0.1} \mathrm{O}_{2}$ ), $\mathrm{NaMgMnO}$ (for $\mathrm{Na}_{x} \mathrm{Mg}_{0.11} \mathrm{Mn}_{0.89} \mathrm{O}_{2}$ ), $\mathrm{NaMnFeNiO}$ (for $\mathrm{NaMn}_{0.25} \mathrm{Fe}_{0.5} \mathrm{Ni}_{0.25} \mathrm{O}_{2}$ ), LiNiCoAIO (for $\mathrm{LiNi}_{0.8} \mathrm{Co}_{0.15} \mathrm{Al}_{0.05} \mathrm{O}_{2}$ ), and LiNiMnCoO (for $\mathrm{LiNi}_{1 / 3} \mathrm{Mn}_{1 / 3} \mathrm{Co}_{1 / 3} \mathrm{O}_{2}$ )

high voltages, some compounds reach gravimetric energy densities of $600-900 \mathrm{Wh} \mathrm{kg}^{-1}$, which is well above the state-ofthe-art cathode materials for NIBs. With respect to the high voltages, it has to be mentioned that some of these compounds may pose problems with respect to currently available electrolytes, due to the limited voltage stability window of the latter ones. ${ }^{51}$

To assert the feasibility of a synthesis of the newly predicted compounds, we have investigated their stability with respect to the boundary phases $\mathrm{MF}_{2}$ and $\mathrm{M}^{\prime} \mathrm{F}_{3}$, which would be typical starting phases for an experimental synthesis. Indeed, all compounds are stable with respect to these fluoride phases. On the other hand, some phases are slightly metastable with respect to decomposition in other SMFs. Nevertheless, we can conclude that the predicted compounds are very likely to be synthesizable (see Fig. S6 for further details).

For comparison, we have performed additional GGA+U calculations for the determination of the average voltage (see Table S2). These calculations generally lead to somewhat increased voltages such that the stability of electrolytes indeed may have to be considered as an issue for several of the compounds. Furthermore, some of the investigated compounds may be strong fluorination agents, which could result in the undesirable fluorination of conductive carbon additives. ${ }^{53,54}$

Apart from purely energetic considerations, kinetics is also an important factor for the performance of cathode material. Consequently, we have investigated the diffusion barriers for the selected materials. For the $\mathrm{Na}_{2} \mathrm{MgAlF}_{7}$ prototype structure, the distance between neighboring $\mathrm{Na} 1$ sites amounts to $\sim 3.5 \AA$ and is much shorter than the $\sim 5.1 \AA$ between two Na2 sites (Fig. $4 a, b$ ). The distance between neighboring $\mathrm{Na} 1$ and $\mathrm{Na} 2$ sites, on the other hand, is also in the order of $3.5 \AA$. As discussed in the description of the weberite structure, the Na1 sites form a $2 D$ network that is interconnected and allows for diffusion with rather small activation barriers (see below), meaning that $50 \%$ of the $\mathrm{Na}$ atoms can rather easily be extracted. Along the significantly longer $\mathrm{Na} 2-\mathrm{Na} 2$ pathway, we find the diffusion to be hindered by a significantly increased barrier in the parent compound (and a few other test cases such as $\mathrm{Mg}-\mathrm{Sc}$ or $\mathrm{Zn}-\mathrm{Ti}$ ), see Fig. $4 \mathrm{~d}$ and Fig. $\mathrm{S6}$. Consequently, we have not further considered this diffusion channel.

The Na1-Na2 path, on the other hand, shows a similar barrier height as that of the Na1-Na1 path in the parent compound (Fig. 4d). Here, however, a significant contributor to the barrier is the energy difference between the initial and the final state of the diffusion process. This energy difference is because a vacancy on a $\mathrm{Na} 1$ site is found to be energetically more favorable than a vacancy on a Na2 site. The barrier can thus be interpreted as consisting of a static and a kinetic contribution. And fast diffusion will only be possible if both contributions are reasonably small. Therefore, the feasibility of the $\mathrm{Na} 1-\mathrm{Na} 2$ diffusion can be estimated by the energy difference between the initial and final state of the Na1-Na2 jump. Consequently, the diffusion behavior of weberites can be estimated by two parameters, the activation energy of the $\mathrm{Na1-Na1}$ diffusion path $\Delta E_{\mathrm{A}, \mathrm{Na} \text { 1) }}$ and the energy difference between a vacancy on the $\mathrm{Na} 1$ site and a vacancy on the $\mathrm{Na} 2$ site $\Delta E_{\mathrm{vac}(\mathrm{Na} 1-\mathrm{Na} 2)}$.

In Fig. 5a, we present the calculated diffusion barriers for the selected compounds (Na1-Na1). Interestingly, most diffusion barriers are $<0.5 \mathrm{eV}$, with remarkably low barriers of $<0.2 \mathrm{eV}$ for several newly predicted Ti-containing compounds. Among the known compounds, there is clear evidence for Sc having a positive impact on the diffusion behavior since three of the known compounds with the lowest observed barriers contain redoxinactive Sc. Here the Co-Sc compound is the best performing material with a barrier of $0.3 \mathrm{eV}$. For several of the newly predicted compounds, the barriers are even lower, with some Ti-containing compounds such as $\mathrm{Mn}-\mathrm{Ti}, \mathrm{Co}-\mathrm{Ti}$, and $\mathrm{Zn}-\mathrm{Ti}$ showing values $<0.2 \mathrm{eV}$. This points to the positive impact of $\mathrm{Ti}^{3+}$, which, in contrast to $\mathrm{Sc}$, is furthermore a redox-active $\mathrm{TM}$ and thus might 
a)

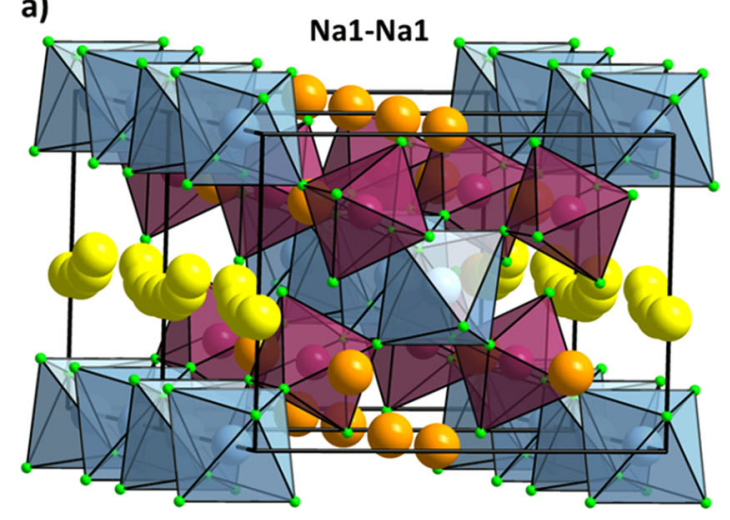

c)

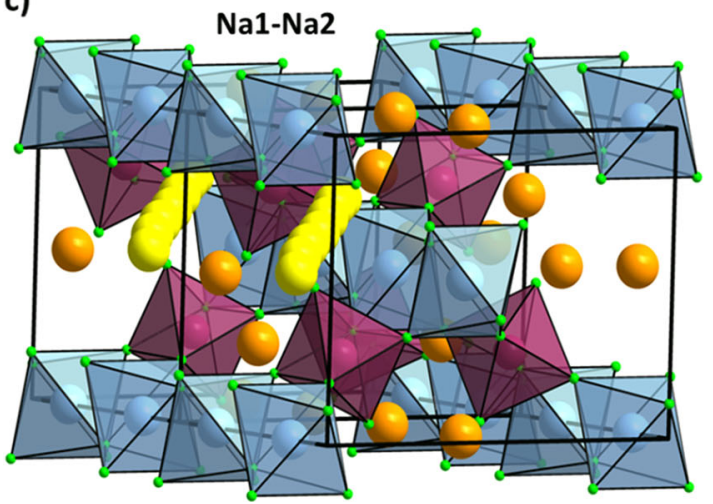

b)

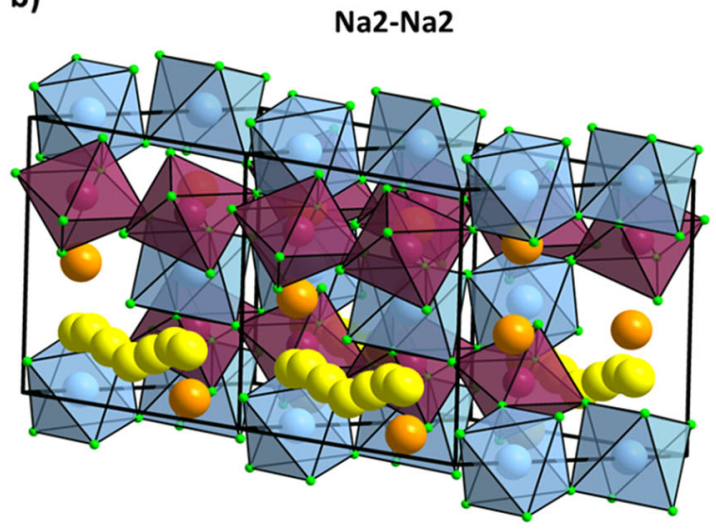

d)

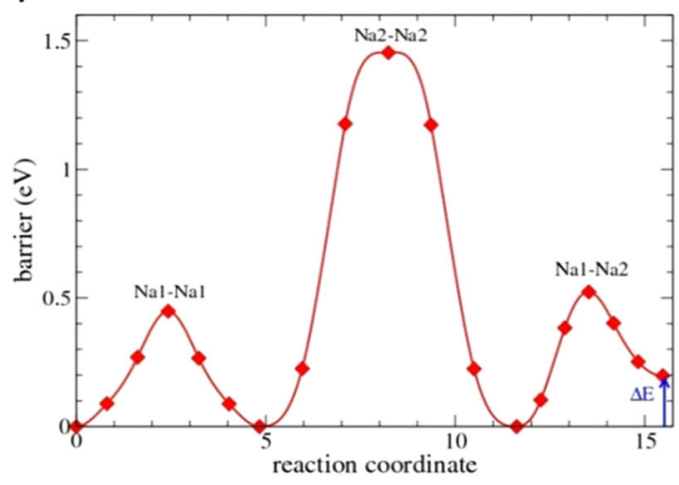

Fig. 4 Possible diffusion pathways in weberites of space group Imma, as determined by the nudged elastic band (NEB) method. Na1-Na1, $\mathrm{Na} 2-\mathrm{Na} 2$, and $\mathrm{Na} 1-\mathrm{Na} 2$ diffusion channels are shown in a-c. The corresponding diffusion barriers for the parent compound $\mathrm{Na}_{2} \mathrm{MgAlF}_{7}$, also obtained from NEB calculations, are shown in d

allow for further sodium extraction. For the compounds, which were reported to crystallize in a weberite modification with space group other than Imma from experimental studies, we find the $\mathrm{Mn}-\mathrm{V}$ composition to have the lowest barrier $(0.23 \mathrm{eV})$, thus indicating that Mn-containing compounds may show fast diffusion.

In Fig. 5b, the second descriptor for Na diffusion in weberites,

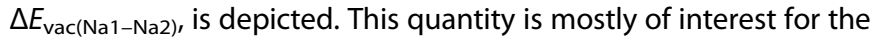
extraction of more than one $\mathrm{Na}$ per f.u. For the known compounds, $\Delta E_{\mathrm{vac}(\mathrm{Na} 1-\mathrm{Na} 2)}$ lies below about $0.35 \mathrm{eV}$. However, for the compounds with possible double redox ( $\mathrm{Mg}-\mathrm{V}$ (accessing $\mathrm{V}^{5+}$ ), $\mathrm{Ni}-\mathrm{Fe}$, and $\mathrm{Ni}-\mathrm{Co}$ ) the diffusion barriers for the $\mathrm{Na} 1$ diffusion are comparably high, such that none of the known compounds seems to allow for easy extraction of two Na per f.u. Therefore, with respect to easy Na diffusion, the Co-Sc weberite seems to be best

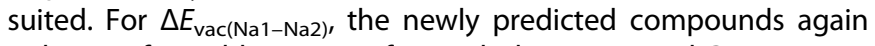
indicate a favorable impact of $\mathrm{Ti}$, such that $\mathrm{Mn}-\mathrm{Ti}$ and $\mathrm{Co}-\mathrm{Ti}$ remain good candidates. Finally, in the case of the known compounds that do not crystallize with Imma symmetry experimentally, $\mathrm{Fe}-\mathrm{Ti}$ is the candidate with the best diffusion properties. For these considerations, one has to keep in mind that only one Na1-Na2 jump is necessary to move an $\mathrm{Na}$ ion from an $\mathrm{Na} 2$ site to the fast conducting $\mathrm{Na} 1$ sublattice. $\mathrm{Na}$ diffusion barriers reported for polyanionic compounds such as $\mathrm{NaFePO}_{4}$ and $\mathrm{Na}_{1.5} \mathrm{VPO}_{5} \mathrm{~F}_{0.5}$ amount to $\sim 375$ and $300 \mathrm{meV}$, respectively. ${ }^{55-57}$ For $\mathrm{Na}_{2} \mathrm{FeP}_{2} \mathrm{O}_{7}$, barriers of $\sim 500 \mathrm{meV}$ are found. ${ }^{58}$ Thus the diffusion barriers in most weberites fall in the typical range of $300-400 \mathrm{meV}$, while the Ti-containing compounds have barriers even lower than the divacancy mechanism in layered $\mathrm{NaCoO}_{2}$, for which barriers of $\sim 180$ meV have been calculated. ${ }^{55}$

\section{DISCUSSION}

For the practical use of cathode material, a further important criterion is the volume change under sodiation/desodiation. From our density functional theory (DFT) calculations, the volume change is directly accessible and is depicted in Fig. 6. We indeed find that most of the cathodes show a volume change $<10 \%$ for full desodiation. All of the compounds with only one redox center even remain below a $5 \%$ volume change. For most compounds with two redox centers, we also evidence $<5 \%$ volume change when only half of the $\mathrm{Na}$ is removed (not shown). Only under full desodiation, we find several compounds that show an increased volume change. Especially for some of the proposed Ti-containing phases, such as the $\mathrm{Co}-\mathrm{Ti}, \mathrm{Ni}-\mathrm{Ti}$, and $\mathrm{Cu}-\mathrm{Ti}$ compounds, volume changes of $>10 \%$ are observed for full desodiation. Interestingly, $\mathrm{Mg}$ - and $\mathrm{Zn}$-containing compounds tend to increase the volume upon desodiation, which indicates that by doping with these elements the volume decrease observed for other compounds may be compensated. Hence, also in the case of volume change, it seems to be possible to optimize the performance of a given compound by alloying. Again it is interesting to seek comparison with other cathode materials for NIBs. Indeed, large volume changes were observed in desodiated layered cathode materials, with, e.g., P2-type $\mathrm{Na}_{2 / 3} \mathrm{Ni}_{1 / 3} \mathrm{Mn}_{2 / 3} \mathrm{O}_{2}$ and $\mathrm{Na}_{0.7} \mathrm{Fe}_{0.4} \mathrm{Mn}_{0.4} \mathrm{Co}_{0.2} \mathrm{O}_{2}$ showing volume changes of $23.2 \%$ and $14.8 \%$, respectively. ${ }^{59,60}$ On the other hand, low volume changes were reported for polyanionic compounds, such as $\mathrm{Na}_{4} \mathrm{Fe}_{3}\left(\mathrm{PO}_{4}\right)_{2} \mathrm{P}_{2} \mathrm{O}_{7}(4 \%), \mathrm{Na}_{2} \mathrm{Fe}^{\text {Il- }}$ $\mathrm{PO}_{4} \mathrm{~F}(3.7 \%)$, and $\mathrm{Na}_{3} \mathrm{~V}_{2}\left(\mathrm{PO}_{4}\right)_{2} \mathrm{~F}_{3}(-3 \%)$. ${ }^{22,61}$ Thus, also in terms of volume change, weberites seem to be promising cathode materials, especially when partial desodiation and alloying are considered. 

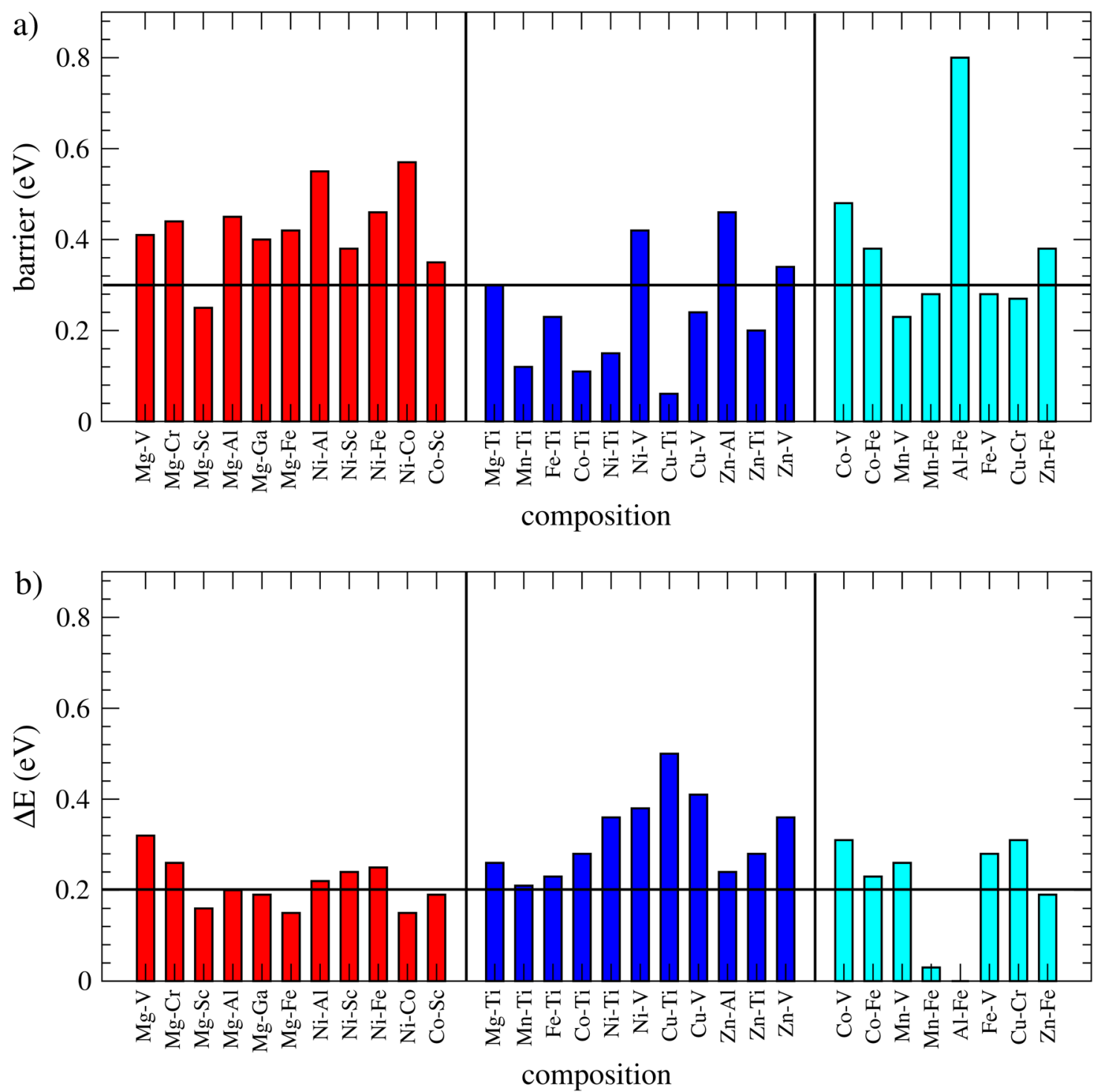

Fig. 5 a Diffusion barriers of the Na1-Na1 diffusion for selected compounds. b Energy difference between an initial and final state for $\mathrm{Na} 1-\mathrm{Na} 2$ diffusion as an indicator for accessibility of the second $\mathrm{Na}$ ion. The color code corresponds to compounds known (red), unknown (blue), and known in different space group (cyan) as introduced in Fig. 3

Stability toward the liquid electrolyte plays an important role in determining the electrochemical activity and cycling stability of the material under study. The sodium extraction/insertion potential of weberite-type SMFs is high, often exceeding $4.5 \mathrm{~V}$. Electrolytes that are stable up to $5.0 \mathrm{~V}$ vs. $\mathrm{Na} / \mathrm{Na}^{+}$are necessary to explore the full potential of sodium transition metal fluorides. Therefore, it is important to shed light on possible electrolytes that could be compatible with SMFs. Sodium was reversibly inserted in $\mathrm{Na}_{4} \mathrm{Ni}_{3}\left(\mathrm{PO}_{4}\right)_{2}\left(\mathrm{P}_{2} \mathrm{O}_{7}\right)$, a $4.8 \mathrm{~V}$ cathode material using NaTFSI:Py ${ }_{13} \mathrm{FSI}$ (1:9 mole ratio) electrolyte. ${ }^{55}$ The electrolyte is stable up to $5.1 \mathrm{~V}$ vs. $\mathrm{Na} / \mathrm{Na}^{+}$, making it a potential choice for the high-voltage weberite-type compounds. Recently, highly concentrated electrolytes (HCEs), made a tremendous impact in electrochemical energy storage due to their unusual properties like an expanded electrochemical window, high reductive stability, high oxidative and thermal stability, low interfacial resistance, suppressed aluminum corrosion, and low dissolution of electrode materials. ${ }^{62}$ For example, the HCE of LiFSI dissolved in dimethyl carbonate was found to suppress Al corrosion, and the $4.7 \mathrm{~V}$ cathode $\mathrm{LiNi}_{0.5} \mathrm{Mnn}_{1.5} \mathrm{O}_{4}$ could be cycled well in this electrolyte, ${ }^{58}$ whereas no stable cycling was found in the corresponding dilute electrolytes. The unusual properties discovered for HCEs in LIBs are also applicable to NIBs. For example, HCEs of NaFSI or NaTFSI salt dissolved in the mixture of carbonate solvents could overcome the Al corrosion and improve the electrochemical stability window. However, HCEs show low ionic conductivity and high viscosity compared to the corresponding dilute electrolytes, therefore new separator designs are needed.

In summary, we have investigated a series of weberite-type SMFs as cathode materials for NIBs. The high energy density in combination with the low activation barriers for sodium diffusion makes these compounds interesting to be studied experimentally in future. While we have limited our study to the investigation of only a certain number of compounds, the playground for these materials in combination with their variety of possible modifications might be even larger. Apart from other element combination, we highlight that it may also be of interest to populate each of the metal sublattices by more than one species, which could allow for further optimization of the compounds by facilitating faster diffusion pathways while maintaining high energy density. Following this strategy, we suggest to alloy some high-energy density materials with a certain amount of $\mathrm{Ti}$ to create fast 


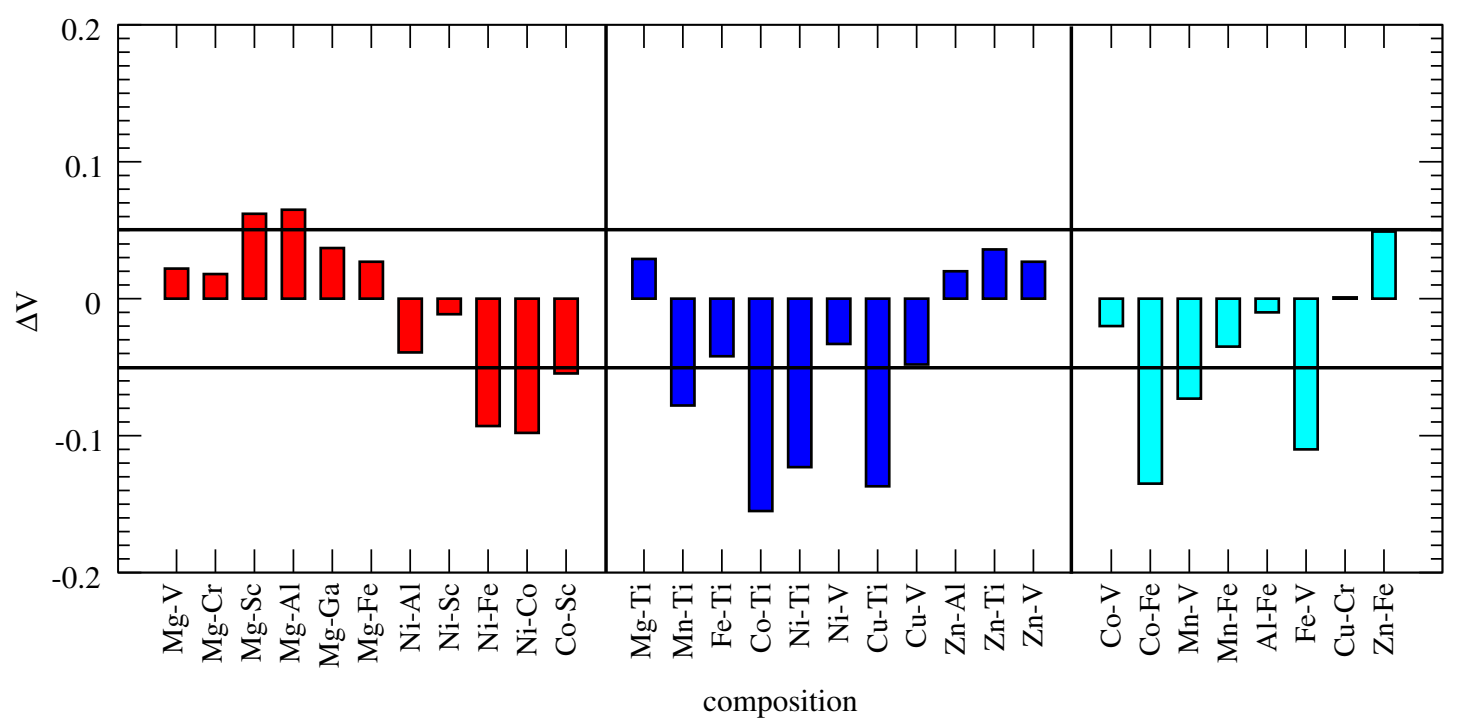

Fig. 6 Volume changes under desodiation. Negative volume changes mean decreasing volume, while positive volume change stands for increasing volume under desodiation (with respect to the volume of the fully sodiated phase) The desodiated state is considered with respect to the redox centers (i.e., either one or two Na per f.u. are extracted). The Mg-Al, Mg-Ga, Mg-Sc, and Zn-Al compounds are in principle not redox active-for these cases, one Na per f.u. was removed to elaborate the impact of these elements. The color code corresponds to compounds known (red), unknown (blue), and known in different space group (cyan) as introduced in Fig. 3

diffusion channels. With the potential of these materials being demonstrated from the theoretical viewpoint, the authors aim to trigger the synthesis and experimental testing of these compounds in future studies.

\section{METHODS}

To enable quantitative predictions, we have computationally investigated a series of weberite structures with respect to their potential as cathode materials. For this purpose, we have conducted quantum mechanical calculations, using the DFT code VASP. ${ }^{63}$ VASP is a plane wave code, which describes the electron-ion interaction via pseudopotentials. For the present study, the projector-augmented wave method was applied for this task, ${ }^{64}$ while exchange and correlation were accounted for by the general gradient approximation (GGA), using the PBE functional introduced by Perdew, Burke, and Ernzerhof. ${ }^{65}$ Spin-polarized calculations were conducted with a $5 \times 5 \times 5 \mathrm{k}$-point mesh and a plane wave cutoff energy of $600 \mathrm{eV}$. The parent compound $\mathrm{Na}_{2} \mathrm{MgAlF}_{7}$ was used as starting configuration for fully sodiated and completely desodiated structures that then were optimized with respect to lattice parameter and atomic positions. The DFT energies of sodiated and (partially) desodiated structure then allow for the determination of the OCV of the respective compound by applying the following equation: ${ }^{66,67}$

$U[V]=\frac{E\left(N a_{2} M M^{\prime} F_{7}\right)-\left[E\left(N a_{x} M M^{\prime} F_{7}\right)+(2-x) E\left(N a_{b c c}\right)\right]}{-(2-x) \mathrm{F}}$

Here $E\left(N a_{2} M M^{\prime} F_{7}\right), E\left(N a_{x} M M^{\prime} F_{7}\right)$, and $E\left(N a_{b c c}\right)$ are the total energies of sodiated structure, (partially) desodiated structure and metallic sodium, respectively, while $\mathrm{F}$ is the Faraday constant. It has to be pointed out that, in the case of two redox-active elements $\left(M, M^{\prime}\right)$ (or one redox center that allows for a two-fold oxidation), the completely desodiated structure was considered (i.e., $N a_{x} M M^{\prime} F_{7}$ with $x=0$ ), while for one redox-active species only half desodiated structures were taken into account (i.e., $N a_{x} M M^{\prime} F_{7}$ with $x=1$ ). For the half desodiated case, we have compared structures with empty $\mathrm{Na} 1$ sites and empty $\mathrm{Na} 2$ sites and taken the one with the lower energy for determining the corresponding voltage. For most compounds emptying the Na1 site is energetically more favorable, however, the differences are typically small (see Fig S4).

For the determination of the diffusion barriers, the climbing image nudged elastic band method was used, ${ }^{68,69}$ which allows accessing the minimum energy path for a given diffusion process. By providing initial and final state of the diffusion process, we have investigated three different diffusion channels in the parent compound $\mathrm{Na}_{2} \mathrm{MgAlF}_{7}$ : (1) the diffusion path between two Na1 sites, (2) the one between two Na2 sites, and (3) the path that connects $\mathrm{Na} 1$ with $\mathrm{Na} 2$ sites. The diffusion pathways were obtained by removing either an atom on a $\mathrm{Na} 1$ or on a $\mathrm{Na} 2$ site, such that the barriers correspond to the case of an almost fully sodiated structure $\left(\mathrm{Na}_{1.75} \mathrm{MM}^{\prime} \mathrm{F}_{7}\right)$.

\section{DATA AVAILABILITY}

Supplementary Information is available at the online version of the paper. Reprints and permissions information is available at www.nature.com/reprints. Readers are welcome to comment on the online version of the paper correspondence and requests for materials should be addressed to M.A.R. (munnangi.reddy@kit.edu).

\section{ACKNOWLEDGEMENTS}

This work was performed on the computational resource ForHLR II funded by the Ministry of Science, Research and the Arts Baden-Württemberg and DFG ("Deutsche Forschungsgemeinschaft"). This work contributes to the research performed at CELEST (Center for Electrochemical Energy Storage Ulm-Karlsruhe). We acknowledge support by Deutsche Forschungsgemeinschaft and Open Access Publishing Fund of Karlsruhe Institute of Technology.

\section{AUTHOR CONTRIBUTIONS}

M.A.R. conceived the whole idea for the project. H.E. performed all the DFT calculations. O.C. performed the structural analysis. M.A.R. and H.E. discussed the results and wrote the manuscript with contributions from O.C.

\section{ADDITIONAL INFORMATION}

Supplementary Information accompanies the paper on the npj Computational Materials website (https://doi.org/10.1038/s41524-019-0166-3).

Competing interests: The authors declare no competing interests.

Publisher's note: Springer Nature remains neutral with regard to jurisdictional claims in published maps and institutional affiliations.

\section{REFERENCES}

1. Slater, M. D., Kim, D., Lee, E. \& Johnson, C. S. Sodium-ion batteries. Adv. Funct. Mater. 23, 947-958 (2013) 
2. Yabuuchi, N., Kubota, K., Dahbi, M. \& Komaba, S. Research development on sodium-ion batteries. Chem. Rev. 114, 11636-11682 (2014).

3. Clément, R. J., Bruce, P. G. \& Grey, C. P. Review-Manganese-based P2-type transition metal oxides as sodium-ion battery cathode materials. J. Electrochem. Soc. 162, A2589-A2604 (2015).

4. Okoshi, M., Yamada, Y., Yamada, A. \& Nakai, H. Theoretical analysis on desolvation of lithium, sodium, and magnesium cations to organic electrolyte solvents. J. Electrochem. Soc. 160, A2160-A2165 (2013).

5. Delmas, C., Fouassier, C. \& Hagenmuller, P. Structural classification and properties of the layered oxides. Phys. B+C 99, 81-85 (1980).

6. Vassilaras, P., Ma, X., Li, X. \& Ceder, G. Electrochemical properties of monoclinic $\mathrm{NaNiO}_{2}$. J. Electrochem. Soc. 160, A207-A211 (2013).

7. Kikkawa, S., Miyazaki, S. \& Koizumi, M. Deintercalated $\mathrm{NaCoO}_{2}$ and $\mathrm{LiCoO}_{2}$. J. Solid State Chem. 62, 35-39 (1986).

8. $\mathrm{Ma}, \mathrm{X}$., Chen, H. \& Ceder, G. Electrochemical properties of monoclinic $\mathrm{NaMnO}_{2}$. J. Electrochem. Soc. 158, A1307-A1312 (2011).

9. Komaba, S., Takei, C., Nakayama, T., Ogata, A. \& Yabuuchi, N. Electrochemical intercalation activity of layered $\mathrm{NaCrO}_{2}$ vs. $\mathrm{LiCrO}_{2}$. Electrochem. Commun. 12, 355-358 (2010).

10. Lu, Z. \& Dahn, J. R. In situ X-ray diffraction study of $P 2 N \mathrm{Na}_{2 / 3}\left[\mathrm{Ni}_{1 / 3} \mathrm{Mn}_{2 / 3}\right] \mathrm{O}_{2}$. J. Electrochem. Soc. 148, A1225-A1229 (2001).

11. Yoshida, $\mathrm{H}_{\text {., }}$ Yoshida, $\mathrm{H}$., Yabuuchi, N. \& Komaba, $\mathrm{S}$. $\mathrm{NaFe}_{0.5} \mathrm{CO}_{0.5} \mathrm{O}_{2}$ as high energy and power positive electrode for $\mathrm{Na}$-ion batteries. Electrochem. Commun. 34, 60-63 (2013).

12. Kubota, K. et al. New insight into structural evolution in layered $\mathrm{NaCrO}_{2}$ during electrochemical sodium extraction. J. Phys. Chem. C 119, 166-175 (2015).

13. Bo, S.-H., Li, X., Toumar, A. J. \& Ceder, G. Layered-to-rock-salt transformation in desodiated $\mathrm{Na}_{x} \mathrm{CrO}_{2}$ (x 0.4). Chem. Mater. 28, 1419-1429 (2016).

14. Sathiya, M., Hemalatha, K., Ramesha, K., Tarascon, J. M. \& Prakash, A. S. Synthesis, structure, and electrochemical properties of the layered sodium insertion cathode material: $\mathrm{NaNi}_{1 / 3} \mathrm{Mn}_{1 / 3} \mathrm{Co}_{1 / 3} \mathrm{O}_{2}$. Chem. Mater. 24, 1846-1853 (2012).

15. Kim, D. et al. Layered $\mathrm{NaNi}_{1 / 3} \mathrm{Fe}_{1 / 3} \mathrm{Mn}_{1 / 3} \mathrm{O}_{2}$ cathodes for $\mathrm{Na}$-ion battery application. Electrochem. Commun. 18, 66-69 (2012).

16. $\mathrm{Li}$, X. et al. O3-type $\mathrm{Na}\left(\mathrm{Mn}_{0.25} \mathrm{Fe}_{0.25} \mathrm{Co}_{0.25} \mathrm{Ni}_{0.25}\right) \mathrm{O}_{2}$ : a quaternary layered cathode compound for rechargeable $\mathrm{Na}$ ion batteries. Electrochem. Commun. 49, 51-54 (2014).

17. Yabuuchi, $\mathrm{N}$. et al. $\mathrm{P} 2$-type $\mathrm{Na}_{\mathrm{x}}\left[\mathrm{Fe}_{1 / 2} \mathrm{Mn}_{1 / 2}\right] \mathrm{O}_{2}$ made from earth-abundant elements for rechargeable Na batteries. Nat. Mater. 11, 512-517 (2012).

18. Billaud, J. et al. $\mathrm{Na}_{0.67} \mathrm{Mn}_{1-\mathrm{x}} \mathrm{Mg}_{\mathrm{x}} \mathrm{O}_{2}(0 \leq \mathrm{x} \geq 0.2)$ : a high capacity cathode for sodium-ion batteries. Energy Environ. Sci. 7, 1387-1391 (2014).

19. Keller, M., Buchholz, D. \& Passerini, S. Layered Na-ion cathodes with outstanding performance resulting from the synergetic effect of mixed $\mathrm{P}$ - and O-type phases. Adv. Energy Mater. 6, 1501555 (2016).

20. Kalapsazova, M. L. et al. Effects of the particle size distribution and of the electrolyte salt on the intercalation properties of $\mathrm{P} 3-\mathrm{Na}_{2 / 3} \mathrm{Ni}_{1 / 2} \mathrm{Mn}_{1 / 2} \mathrm{O}_{2}$. J. Phys. Chem. C 121, 5931-5940 (2017).

21. Kalapsazova, M. et al. Combined use of EPR and ${ }^{23}$ Na MAS NMR spectroscopy for assessing the properties of the mixed cobalt-nickel-manganese layers of P3$\mathrm{Na}_{y} \mathrm{Co}_{1-2 x} \mathrm{Ni}_{x} \mathrm{Mn}_{x} \mathrm{O}_{2}$. Phys. Chem. Chem. Phys. 19, 27065-27073 (2017).

22. Ellis, B. L., Makahnouk, W. R. M., Makimura, Y., Toghill, K. \& Nazar, L. F. A multifunctional $3.5 \mathrm{~V}$ iron-based phosphate cathode for rechargeable batteries. Nat Mater. 6, 749-753 (2007)

23. Zhu, C., Song, K., van Aken, P. A., Maier, J. \& Yu, Y. Carbon-coated $\mathrm{Na}_{3} \mathrm{~V}_{2}\left(\mathrm{PO}_{4}\right)_{3}$ embedded in porous carbon matrix: an ultrafast Na-storage cathode with the potential of outperforming Li cathodes. Nano Lett. 14, 2175-2180 (2014).

24. Liu, Q. et al. Carbon-coated $\mathrm{Na}_{3} \mathrm{~V}_{2}\left(\mathrm{PO}_{4}\right)_{2} \mathrm{~F}_{3}$ nanoparticles embedded in a mesoporous carbon matrix as a potential cathode material for sodium-ion batteries with superior rate capability and long-term cycle life. J. Mater. Chem. A $\mathbf{3}$, 21478-21485 (2015).

25. Kawabe, $\mathrm{Y}$. et al. Synthesis and electrode performance of carbon coated $\mathrm{Na}_{2} \mathrm{Fe}$ $\mathrm{PO}_{4} \mathrm{~F}$ for rechargeable $\mathrm{Na}$ batteries. Electrochem. Commun. 13, 1225-1228 (2011).

26. Chen, $\mathrm{H}$. et al. Sidorenkite $\left(\mathrm{Na}_{3} \mathrm{MnPO}_{4} \mathrm{CO}_{3}\right)$ : a new intercalation cathode material for Na-ion batteries. Chem. Mater. 25, 2777-2786 (2013).

27. Barpanda, P., Oyama, G., Nishimura, S.-i, Chung, S.-C. \& Yamada, A. A 3.8-V earthabundant sodium battery electrode. Nat. Commun. 5, 4358 (2014).

28. Bianchini, M., Xiao, P., Wang, Y. \& Ceder, G. Additional sodium insertion into polyanionic cathodes for higher-energy Na-ion batteries. Adv. Energy Mater. 7, 1700514 (2017).

29. Anji Reddy, M., Euchner, H., Witter, R. \& Clemens, O. Structure and electrochemical properties of $\mathrm{Na}_{2 \pm x} \mathrm{~V}_{3} \mathrm{P}_{2} \mathrm{O}_{13}(\mathrm{x}=0$ and 1): a promising cathode material for sodium-ion batteries. J. Mater. Chem. A 6, 6947-6958 (2018).

30. Gocheva, I. D. et al. Mechanochemical synthesis of $\mathrm{NaMF}_{3}(\mathrm{M}=\mathrm{Fe}, \mathrm{Mn}, \mathrm{Ni})$ and their electrochemical properties as positive electrode materials for sodium batteries. J. Power Sources 187, 247-252 (2009).

31. Dimov, N. et al. Transition metal $\mathrm{NaMF}_{3} \mathrm{Compounds}$ as model systems for studying the feasibility of ternary Li-M-F and Na-M-F single phases as cathodes for lithium-ion and sodium-ion batteries. Electrochim. Acta 110, 214-220 (2013)

32. Yamada, Y., Doi, T., Tanaka, I., Okada, S. \& Yamaki, J.-i Liquid-phase synthesis of highly dispersed $\mathrm{NaFeF}_{3}$ particles and their electrochemical properties for sodium-ion batteries. J. Power Sources 196, 4837-4841 (2011).

33. Kitajou, A. et al. Novel synthesis and electrochemical properties of perovskitetype $\mathrm{NaFeF}_{3}$ for a sodium-ion battery. J. Power Sources 198, 389-392 (2012).

34. Haegele, R., Verscharen, W., Babel, D., Dance, J.-M. \& Tressaud, A. Die verfeinerung der weberitstruktur der verbindung $\mathrm{Na}_{2} \mathrm{NiFeF}_{7}$. J. Solid State Chem. 24, 77-84 (1978).

35. Knop, O., Cameron, T. S. \& Jochem, K. What is the true space group of weberite? J. Solid State Chem. 43, 213-221 (1982).

36. Cai, L. \& Nino, J. C. Complex ceramic structures. I Weberites. Acta Cryst. B65 269-290 (2009).

37. Subramanian, M. A., Marshall, W. J., Hoffmann, R.-D. \& Sleight, A. W. Synthesis and structure of some $M^{\prime \prime} / M^{\prime \prime \prime}$ mixed fluorides with pyrochlore and weberite related structures. Z. Naturforsch. B 61, 808-812 (2006).

38. Badway, F., Pereira, N., Cosandey, F. \& Amatucci, G. G. Carbon-metal fluoride nanocomposites: structure and electrochemistry of $\mathrm{FeF}_{3}: \mathrm{C}$. J. Electrochem. Soc. 150, A1209-A1218 (2003).

39. Plitz, I. et al. Structure and electrochemistry of carbon-metal fluoride nanocomposites fabricated by solid-state redox conversion reaction. J. Electrochem. Soc. 152, A307-A315 (2005).

40. Martha, S. K. et al. Electrode architectures for high capacity multivalent conversion compounds: iron (II and III) fluoride. RSC Adv. 4, 6730-6737 (2014).

41. Anji Reddy, M. \& Fichtner, M. Batteries based on fluoride shuttle. J. Mater. Chem 21, 17059-17062 (2011).

42. Rongeat, C., Anji Reddy, M., Witter, R. \& Fichtner, M. Nanostructured fluorite-type fluorides as electrolytes for fluoride ion batteries. J. Phys. Chem. C 117, 4943-4950 (2013).

43. Rongeat, C., Anji Reddy, M., Witter, R. \& Fichtner, M. Solid electrolytes for fluoride ion batteries: ionic conductivity in polycrystalline tysonite-type fluorides. ACS Appl. Mater. Interfaces 6, 2103-2110 (2014).

44. Pereira, N., Badway, F., Wartelsky, M., Gunn, S. \& Amatucci, G. G. Iron oxyfluorides as high capacity cathode materials for lithium batteries. J. Electrochem. Soc. 156 A407-A416 (2009).

45. Li, T., Li, L., Cao, Y. L., Ai, X. P. \& Yang, H. X. Reversible three-electron redox behaviors of $\mathrm{FeF}_{3}$ nanocrystals as high-capacity cathode-active materials for $\mathrm{Li}$ ion batteries. J. Phys. Chem. C 114, 3190-3195 (2010).

46. Li, L., Meng, F. \& Jin, S. High-capacity lithium-ion battery conversion cathodes based on iron fluoride nanowires and insights into the conversion mechanism. Nano Lett. 12, 6030-6037 (2012).

47. Anji Reddy, $M$. et al. $\mathrm{CF}_{\mathrm{x}}$ derived carbon- $\mathrm{FeF}_{2}$ nanocomposites for reversible lithium storage. Adv. Energy Mater. 3, 308-313 (2013).

48. Lieser, G. et al. Sol-gel based synthesis of $\mathrm{LiNiFeF}_{6}$ and its electrochemical characterization. J. Electrochem. Soc. 161, A1071-A1077 (2014).

49. Lieser, G. et al. Direct synthesis of trirutile-type $\mathrm{LiMgFeF}_{6}$ and its electrochemical characterization as positive electrode in lithium-ion batteries. J. Power Sources 274, 1200-1207 (2015).

50. Zhang, $\mathrm{H}$. et al. Exploring the $\mathrm{Ni}$ redox activity in polyanionic compounds as conceivable high potential cathodes for Na rechargeable batteries. NPG Asia Mater. 9, e370 (2017).

51. Ponrouch, A. et al. Non-aqueous electrolytes for sodium-ion batteries. J. Mater Chem. A 3, 22-42 (2015).

52. Doeff, M. in Batteries for Sustainability: Selected Entries from the Encyclopedia of Sustainability Science and Technology (ed. R. J. Brodd) 5-49 (Springer, New York, 2012).

53. Nowroozi, M. A., Ivlev, S., Rohrer, J. \& Clemens, O. $\mathrm{La}_{2} \mathrm{CoO}_{4}$ : a new intercalation based cathode material for fluoride ion batteries with improved cycling stability. J. Mater. Chem. A 6, 4658-4669 (2018).

54. Clemens, O. \& Slater, P. R. Topochemical modifications of mixed metal oxide compounds by low-temperature fluorination routes. Rev. Inorg. Chem. 33 105-117 (2013).

55. Ong, S. P. et al. Voltage, stability and diffusion barrier differences between sodium-ion and lithium-ion intercalation materials. Energy Environ. Sci. 4 3680-3688 (2011).

56. Park, Y.-U. et al. Tailoring a fluorophosphate as a novel $4 \mathrm{~V}$ cathode for lithium-ion batteries. Sci. Rep. 2, 704 (2012).

57. Kim, $\mathrm{H}$. et al. $\mathrm{Na}_{2} \mathrm{FeP}_{2} \mathrm{O}_{7}$ as a promising iron-based pyrophosphate cathode for sodium rechargeable batteries: a combined experimental and theoretical study. Adv. Funct. Mater. 23, 1147-1155 (2013).

58. Wang, J. et al. Superconcentrated electrolytes for a high-voltage lithium-ion battery. Nat. Commun. 7, 12032 (2016).

59. Yoshida, $\mathrm{H}$. et al. $\mathrm{P} 2$-type $\mathrm{Na}_{2 / 3} \mathrm{Ni}_{1 / 3} \mathrm{Mn}_{2 / 3-\mathrm{x}} \mathrm{Ti}_{\mathrm{x}} \mathrm{O}_{2}$ as a new positive electrode for higher energy Na-ion batteries. Chem. Commun. 50, 3677-3680 (2014). 
60. Jung, Y. H., Christiansen, A. S., Johnsen, R. E., Norby, P. \& Kim, D. K. In situ X-ray diffraction studies on structural changes of a p2 layered material during electrochemical desodiation/sodiation. Adv. Fun. Mater. 25, 3227-3237 (2015).

61. Ni, Q., Bai, Y., Wu, F. \& Wu, C. Polyanion-type electrode materials for sodium-ion batteries. Adv. Sci. 4, 1600275 (2015).

62. Yamada, Y. \& Yamada, A. Review-Superconcentrated electrolytes for lithium batteries. J. Electrochem. Soc. 162, A2406-A2423 (2015).

63. Kresse, G. \& Furthmüller, J. Efficient iterative schemes for ab initio total-energy calculations using a plane-wave basis set. Phys. Rev. B 54, 11169 (1996).

64. Kresse, G. \& Joubert, D. From ultrasoft pseudopotentials to the projector augmented-wave method. Phys. Rev. B 59, 1758-1775 (1999).

65. Perdew, J. P., Burke, K. \& Ernzerhof, M. Generalized gradient approximation made simple. Phy. Rev. Lett. 77, 3865-3868 (1996).

66. Urban, A., Seo, D.-H. \& Ceder, G. Computational understanding of Li-ion batteries. Npj Compu. Mater. 2, 16002 (2016).

67. Islam, M. S. \& Fisher, C. A. J. Lithium and sodium battery cathode materials: computational insights into voltage, diffusion and nanostructural properties. Chem. Soc. Rev. 43, 185-204 (2014).

68. Henkelman, G., Uberuaga, B. P. \& Jónsson, H. A climbing image nudged elastic band method for finding saddle points and minimum energy paths. J. Chem. Phys. 113, 9901-04 (2000)
69. Jónsson, H., Mills, G. \& Jacobsen, K. W. Nudged elastic band method for finding minimum energy paths of transitions. In Proc. International School of Physics (eds Berne, B. J. \& Coker, D. F.) 385-404 (World Scientific Publishing Co. Pte. Ltd., Singapore, 1998).

(i) Open Access This article is licensed under a Creative Commons Attribution 4.0 International License, which permits use, sharing, adaptation, distribution and reproduction in any medium or format, as long as you give appropriate credit to the original author(s) and the source, provide a link to the Creative Commons license, and indicate if changes were made. The images or other third party material in this article are included in the article's Creative Commons license, unless indicated otherwise in a credit line to the material. If material is not included in the article's Creative Commons license and your intended use is not permitted by statutory regulation or exceeds the permitted use, you will need to obtain permission directly from the copyright holder. To view a copy of this license, visit http://creativecommons. org/licenses/by/4.0/.

(c) The Author(s) 2019 